This is an Author's Original Manuscript of an article whose final and definitive form has been published by Taylor \& Francis in the Journal of Electronic Resources Librarianship on 8/17/2015, available online at: http://www.tandfonline.com/10.1080/1941126X.2015.1059650

\title{
Implementation \& Management of a Consortial Demand-Driven E-Books Pilot: The USMAI Experience
}

by Randall A. Lowe (Frostburg State University) and Lynda Aldana (University of Maryland, Baltimore County)

\section{Introduction}

The University System of Maryland and Affiliated Institutions (USMAI) Library Consortium launched a demand-driven (DDA) e-book pilot program in August 2013. Founded in 1988, the consortium provides "unified, cost effective and creative approaches to acquiring, managing, and sharing information and knowledge resources” (USMAI, 2013, December 18). The consortium is comprised of 16 member institutions, including the University of Maryland, several regional comprehensive universities, four historically black colleges and universities, and professional schools in law and the health sciences, thus representing a diverse group of libraries. In addition, the University System of Maryland (USM) has established two higher education centers from which various institutions offer academic programs; each center includes a library. Over 160,000 students are served by USMAI libraries.

USMAI libraries have a long standing commitment to sharing resources among member institutions. In 1992, the consortium initiated the first statewide system in the United States for direct patron requesting of circulating materials, called "Patron-Placed Holds." Requests for materials, primarily books, placed through the consortium's shared online catalog were shipped to the library of the user's choice (USMAI, 2013, December 16). The large-scale commercial distribution of e-books, with titles aggregated and made available to libraries through several 
vendor platforms, provided USMAI with another opportunity to expand shared collection development and resource sharing of monographic materials, this time in an online format.

The addition of over 25,000 e-book titles via a shared DDA collection, made equally available to the students, faculty, and staff of all USMAI institutions, has positioned the consortium to continue its resource sharing mission into the digital age; however, continually evolving acquisition models for e-books have contributed to limiting the amount of content the consortium has been able to make available to its users. While USMAI has been collaborating with vendors and publishers to address these issues during the first two years of its DDA pilot program, the management of the e-books themselves has also presented several challenges. These range from making program profile changes to addressing bibliographic records processing and related workflows. Satisfactory resolution of these e-resource management issues is critical to support a sustainable consortial e-book collection beyond the pilot stage.

\section{Pilot Objectives and Basic Program Requirements}

The initial intent of the e-book pilot was to investigate the feasibility of a consortiumwide DDA program for e-books, to identify advantages and problems experienced, and to determine how to share costs and ownership of e-books equitably among institutions. In addition, data gathering and assessment during the pilot would be used to determine interest in ebooks and usage patterns by the USMAI community. The pilot was centrally funded by the consortium. 
In early 2012, the USMAI Council of Library Directors (CLD) created an E-Book Implementation Group and charged it with investigating and making a recommendation to establish a DDA program for the consortium. The group conducted inquiries of academic ebook aggregators that offered acquisition models that would best meet the requirements of the consortium. First, and foremost, it was vital that every USMAI library have equal access to all of the e-books in the collection, both before and after titles were triggered for purchase by users. In addition, the consortium was not agreeable to paying a multiplier (paying for several copies of a title) when e-books were purchased.

Machovec (2013) provides an overview of some of the most common e-book licensing models used by consortia. These range from subscriptions to packages of e-books to DDA and evidence-based models. DDA programs vary greatly, but the most common model involves applying a multiplier to the retail cost of the each e-book that is triggered for purchase so that the title is available to all libraries in a consortium. A multiplier is equivalent to purchasing extra copies of a title. The size of the multiplier varies by consortium size; USMAI has typically been quoted a multiplier of four to six times retail cost by vendors. Another model, called Limited Access/Lending, does not include a multiplier, but limits the number of uses for each e-book triggered for purchase; additional copies are purchased after this limit is reached. Another model allows for libraries within a consortium to access the e-books within a collection, but purchase triggers and expenditures are managed by each institution separately. Evidenced-based models do not include short-term loans like other DDA models, but require libraries to commit to expending a negotiated minimum amount of funds. Users have access to all titles in a collection 
during the contract period and libraries then select e-books to purchase, typically those receiving the most use.

The availability of reliable and granular usage data was also an important requirement in selecting a vendor with which to partner for the pilot. It was essential that e-book usage be reported by USMAI institution and user type (undergraduate student, graduate student, faculty, and staff) in order to meet the stated objectives of the pilot. Data pertaining to titles that provided librarians with the ability to assess attributes such as subject usage and elements of user behavior (online access vs. downloading, length of title use, printing, etc.) were also important.

\section{USMAI's DDA Model}

Ebook Library, or EBL (now a subsidiary of ProQuest), an early innovator in creating various DDA models, including those supporting consortia, was chosen by the Implementation Group primarily due to their willingness to fashion a program to meet USMAI's basic requirements. They presented USMAI with two different consortial models. The first, called the Limited Access/Lending Model, was piloted by Novanet, a consortium of academic libraries in Nova Scotia; it allowed for a truly shared consortium-wide e-book collection. In this model, every member of the consortium had access to each title in the collection, both before and after purchase; no multiplier was applied to purchases. The consortium determined the number of short term loans (STLs) that would be allowed before a purchase is triggered; a percentage of the cost of an e-book was charged for each seven-day STL. After the selected number of STLs was reached, a purchase would be triggered. For each purchased title, the consortium was granted a 
specific number of one-week loans, usually 14 annually. If a title was loaned more than 14 times within a year, an additional copy would be purchased at list price.

The application of the Limited Access/Lending Model meant that when an e-book was purchased, every member library had access to it and there was no multiplier. This would be an advantage for all USMAI libraries, but especially for the two USM higher education centers, where students from different institutions enroll in the same class and may not have access to the same e-resources, depending on the holdings of their home campuses.

The second model presented by EBL/ProQuest and implemented by the Connecticut College, Trinity College, and Wesleyan University (CTW) Consortium in Connecticut, called for each library set up its own DDA profile of e-books. Libraries within the consortium may sign on and pay for access to the profiles of other institutions or just access their own. In the latter instance, an institution would not have access to materials in the profiles of other member libraries. In this model, the first copy was purchased at list price, but subsequent copies were purchased at progressively increased discounts. For example, the purchase cost of a second copy might be a $25 \%$ discount, the third a $35 \%$ discount, etc. Under this model, not all USMAI institutions would have access to all titles, which presented a significant disadvantage to the USM higher education centers, as noted previously.

In May, 2012, the Implementation Group recommended the Limited Access/Lending Model for USMAI. CLD approved this proposal in September 2012 and allocated $\$ 100,000$ to a pilot program. 


\section{Implementation and E-Book Management Issues}

The Implementation Group spent the next several months developing program parameters, finalizing a contract with EBL/ProQuest, and determining how the e-books would be made available to the users of all libraries in the consortium.

The first steps of this process involved working with EBL/ProQuest to develop a profile for the DDA pilot program. The Implementation Group already knew that USMAI would have one profile for all libraries. The group also decided that only a very small group of Library of Congress subject headings and call number ranges would be excluded from the profile.

EBL/ProQuest assisted in developing a survey to require users to self-identify as an undergraduate student, a graduate student, faculty, or staff upon accessing the collection for the first time since the Implementation Group was interested in collecting data about user types. The group also determined that the collection would consist of titles published from 2012 to the present. The remaining parameters of the USMAI DDA program were:

\section{$\underline{\text { Short Term Loans (STLs) }}$}

- Multiple concurrent accesses for all e-books.

- All institutions had access to the e-books comprising the collection.

- E-books could be browsed for five minutes. After five minutes, users were asked if they wanted to borrow the book. If the answer was yes, an STL was triggered.

- Purchases occurred after the sixth Short Term Loan (STL). 
- When a user downloaded a title, the STL period was one week and it could not be returned early.

- The maximum number of STLs per user was 10 books per day. Subsequent STLs were turned into a mediated request that must be approved by a librarian from the Implementation Group.

- $\quad$ STL requests were mediated if the cost of the STL was above $\$ 35$.

\section{$\underline{\text { Purchased Titles }}$}

- Fourteen one-week loans were available per year per title. If the number of loans was exceeded, a second copy was purchased at list price and carried an additional 14 oneweek loans.

- The default lending model was non-linear, providing multiple concurrent accesses per title.

- All institutions had access to the purchased e-book.

- The upper limit for the list price of titles in the program was $\$ 200$.

The parameters above were written into USMAI's contract and reviewed by the University of Maryland Procurement Office. Upon receiving contract approval, the Implementation Group began work to determine how to provide users with access to the titles. Although the consortium shares an integrated library system, public catalog, link resolver, and authentication protocol, two discovery systems have been implemented by member libraries, WorldCat Local and EBSCO Discovery Service (EDS). This required that access to the e-books be provided via collections that were activated in WorldCat Local and also by loading OCLC-sourced bibliographic records into our catalog. The latter was necessary for libraries using EDS for 
discovery as ProQuest and EBSCO do not provide each other with the full metadata associated with respective their e-resource products.

In order to enable access via the different discovery systems, EBL/ProQuest generates lists of titles weekly that are part of the USMAI collection and sends this list or feed to OCLC. OCLC then uses this information to generate new bibliographic records or a deletions list. Because the USMAI profile is run monthly, most of the time the weekly feed that is sent to OCLC just includes non-owned titles that have been removed. However, one week per month the feed includes new titles that have been added to the program. These files of bibliographic records are then loaded into the USMAI catalog, which in turn means that the titles are visible in EDS for those libraries using this discovery service. Deleted titles are removed from the catalog. For the libraries using WorldCat Local as their preferred discovery layer, these feeds automatically populate collections in the knowledge base.

One of the biggest challenges in managing the e-book collection has been finding a balance between managing the record loads and meeting the needs of the USMAI Metadata Subgroup and individual libraries regarding the bibliographic records. Considerable effort has been undertaken to correct or improve these records. The consortium will eventually need to agree upon a set of standards defining acceptable bibliographic records for e-books. These revised standards should only require a reasonable amount of effort to maintain, given limited staffing at USMAI libraries. Additionally, USMAI has and continues to advocate with vendors and other record providers to ensure that the information being included in the bibliographic records meets nationally accepted standards. When these standards are consistently applied, the records are 
more readily usable and require minimal improvements to make the records as accessible as possible, regardless of the platform. Another possible solution to this problem is to use only one discovery service across the entire consortium that does not require loading bibliographic records into the catalog in order to expose the e-books to users.

After a period of testing access to the e-books in the catalog, WorldCat Local, and EDS, titles were made available to users in August 2013. Initially, the USMAI DDA collection had 6,560 titles available for use.

\section{First Year Pilot Review \& Program Changes}

The Implementation Group routinely collected and monitored usage and expenditure data for the pilot beginning with the commencement of the program. Data collection and analysis focused on the number of title browses, STLs and purchases, as well as expenditures, both consortium-wide and by individual institutions. In addition, usage by publisher, subject, and user type (student, faculty, and staff) was assessed. Evaluation of this data, the availability of content, and management and workflow issues experienced during the first year of the pilot provided the foundation for making decisions regarding continuation of the program.

A formal review of the pilot was conducted at the conclusion of the first academic year during which e-books were made available to users, and included an analysis of usage and expenditure data from August 2013 through May 2014. The 6,560 titles in the pilot came from 32 publishers, a figure that increased to 14,710 by the end of the first ten months of the program. While only $\$ 57,231$, or $57.2 \%$ of the funds allocated for the pilot were expended, users of each 
of the USMAI libraries accessed titles in the collection. Browses, loans, and expenditures by the individual libraries largely followed a model used to determine the percentage each institution contributes to pay for the funding of consortial operations. Should the consortial e-book program continue, but not be centrally-budgeted, this data could be utilized to establish a "fundby-use" model.

$58 \%$ of use occurred in the spring 2014 semester, indicating that users discovered titles in the collection at a greater rate during the second half of the year. Approximately 6,000 users accounted for all e-book browses, loans, and purchases, with $40 \%$ affiliated with the University of Maryland. $56.5 \%$ of users were undergraduate students, $27.3 \%$ graduate students, $9.8 \%$ faculty, and 3.4\% staff. Subject analysis was determined by grouping of Library of Congress Classification numbers for e-books according to tables used in a study of a DDA program at the University of Iowa (Fischer, Wright, Clatanoff, Barton, \& Shreeves, 2012). Use was distributed over wide subject areas, indicating that the program was meeting its objective to provide access to a broad range of titles supporting the various academic and research programs offered at USMAI member institutions.

General use of the shared e-book collection indicated that users across all institutions from the consortium were benefitting from the collection, resulting in a recommendation from the Implementation Group to extend the pilot to a second year funded by an additional $\$ 100,000$, which was approved by CLD; however, a few areas of concern were identified that resulted in program changes and discussions with EBL/ProQuest and publishers. 
Most importantly, USMAI was concerned about the viability of the Limited Access/Lending and other DDA models with publishers. As stated above, only 32 publishers participated with a limited amount of content in this model during the first year of the pilot, which was likely a factor contributing to only $57.2 \%$ of the funds allocated for the program being expended. Of the titles triggering STLs, $92.9 \%$ were used three times or less, with $68.3 \%$ of ebooks used only once. Second copies of titles based upon use where purchased only three times in the first ten months of the program with a fourth title purchased seven times. Data such as this from a consortium would likely not be seen by publishers as contributing to supporting a sustainable business model for DDA, as our research suggests (Bivens-Tatum, 2015; Seger \& Allen, 2011; Wolfman-Arent, 2014).

In fact, as USMAI completed the first year of its pilot program, several publishers suddenly increased one-day STLs prices initially ranging from $10 \%-15 \%$ to $25 \%, 30 \%$, and even $40 \%$ of the list price of an e-book; longer loan periods reached as high as $70 \%-80 \%$ of list price (Wolfman-Arent, 2014). Reaction from the library community was swift and firm and included accusations of price-gouging (Stearns \& Unsworth, 2014). In addition, some publishers participating in the USMAI pilot program began to institute embargoes of front list content, typically of one to two years.

The approach USMAI took to preserving its shared DDA e-book collection in the face a continually changing e-book environment was to (1) make profile adjustments to ensure that the program remained affordable and (2) engage in dialogue with EBL/ProQuest and publishers to fashion workable solutions for the consortium that provide member libraries with a broad range 
of content at a fair price point while simultaneously ensuring that academic publishers continue to have a revenue stream that supports the dissemination of scholarly research in this format. The consortium was willing to make adjustments to its DDA program to attract new publishers. As such, USMAI lowered the number of STLs required to trigger an e-book purchase from six to three, an easy decision to encourage more purchasing since $92.9 \%$ of titles were used three times or less. This change, made in September 2014, helped to protect the consortium against shortterm loan price increases, while providing publishers with more outright sales of e-book titles. In addition, the per title cost ceiling was lowered for two publishers that raised STL prices significantly, and e-books priced above this new limit were removed from the collection; however, both publishers were subsequently approached to discuss the possibility of piloting a "lease-to-own" acquisition model, described in the following section.

The consortium also encouraged EBL/ProQuest to recruit additional publishers to participate in the USMAI program. A list of publishers (primarily university and association presses) was subsequently received from EBL/ProQuest for the consortium to consider adding to its collection profile; the Implementation Group selected publishers for inclusion early in the second year of the pilot.

The Implementation Group also committed to studying and developing sustainable workflow options for the management of the collection in an effort to address the processing issues described above. At the conclusion of the first year of the pilot, USMAI instituted a new working group structure to coordinate much of the business conducted by the consortium. The recommendations developed from this effort will include developing procedures to support the 
continuation of a shared e-book collection for the consortium as well as identifying the appropriate working group(s) to coordinate its management.

\section{Lease-to-Own Pilot}

USMAI has been eager to engage in a dialogue with interested parties to explore ways to make shared DDA collections for consortia a win-win situation for both libraries and publishers. USMAI viewed the fluid DDA e-book market environment as an opportunity to approach EBL/ProQuest with the idea that the consortium would be more willing to accept higher STL prices if publishers would credit the cost of these loans to the final purchase price of the e-books. In traditional DDA models, libraries pay the costs for STLs plus the full purchase price of an ebook, when triggered. Fortunately, EBL/ProQuest identified two academic publishers willing to explore this model - the same two publishers for which the per title cost ceiling was lowered in the USMAI DDA profile due to substantial increases in STL costs.

USMAI collaborated with EBL/ProQuest and the two publishers throughout the fall of 2014 to establish parameters for a model that would allow for increased publisher participation in consortial DDA programs in a manner that addressed both library and consortium budgetary

limitations and publishers' revenue concerns. In exchange for crediting the cost of STLs toward the final purchase price of an e-book, USMAI accepted a multiplier of four for each purchase, essentially acquiring four copies; all titles would continue to be shared by every library in the consortium. The lending model would continue to be non-linear with the number of annual accesses per copy set by the publishers. The consortium would have 800 annual loans for any ebook purchased by one of the publishers (200 for each copy) and 1,300 for the other (325 for 
each copy) before another four copies would be triggered for purchase. Based on past usage statistics, it was estimated that subsequent purchases would be made in few instances for only the most highly used titles. Unfortunately, each publisher also imposed an embargo on its content for this pilot - one and two years, respectively.

USMAI completed an agreement for the lease-to-own model in January 2015, but an adjustment to the EBL/ProQuest contract resulted in a procurement delay that has continued through spring 2015. While disappointing, this delay is one of several e-resources management examples where USMAI has identified the need to establish a central office to handle vendor negotiation and procurement for the consortium. As of this writing, CLD is investigating solutions to address this important issue.

Once the lease-to-own titles are made available to users, data will be collected with use and expenditures compared with e-books of the already established Limited Access/Lending model. After the first six months of the pilot, USMAI intends to meet with EBL/ProQuest and the publishers to discuss usage and expenditure data. It is vital that the consortium share its data with publishers and should reasonably expect the same in return so that this information can be utilized to make informed decisions for the benefit of both parties.

\section{The Future}

As the second year of the consortial e-books pilot comes to a conclusion, usage and expenditure data will continue to be assessed in order to determine the value of the program to USMAI libraries. Expenditures in the second year through April 2015 increased 80\% despite a 
relatively stable number of loans, strongly demonstrating the effect that the upturn in STL prices by publishers has had on library DDA budgets. This clearly indicates a need for libraries and consortia to engage in dialogue with vendors and publishers to explore methods to ensure that DDA remains a viable and sustainable option for providing e-books to users. DDA has presented opportunities to build monographic collections at a rate that is not possible in print format, while simultaneously giving users a voice in determining which titles are purchased and become permanently available. While publishers have been able to recoup some revenue with the rise in STL prices, USMAI is eager to begin its lease-to-own pilot with two publishers as described above as one method to work toward ensuring that this program remains affordable, and thus sustainable, for the consortium.

It also will be important to reach out to each member library in the consortium in order to gauge their level of support for this program. Thirteen of the 16 USMAI libraries responded to an e-resources survey in April 2015 in which they were asked if they would support the shared DDA program becoming a permanent collection development activity for the consortium.

Twelve of the 13 libraries responded positively, with many commenting on the strong value the content provides to their users. In addition to continued feedback with USMAI libraries at a general level, comparing the effectiveness of the consortial initiative with existing individual member DDA programs is planned.

The USMAI DDA pilot program has clearly met consortium resource sharing objectives by making a shared multidisciplinary collection of monographs available to the students, faculty and staff of member institutions; however, the continued availability of content desired by these 
user groups is a concern as the playing field as determined by publishers continues to change. Although rising STL costs are a concern, the program has not exceeded its budget to date. USMAI will continue to reach out to publishers in order to find solutions to keep DDA viable and affordable.

While the benefits of the USMAI DDA e-book program are many, it has not been without several other challenges, in addition to those mentioned previously. Content changes weekly as titles are added to or deleted from the collection. Added titles are easily managed, but deletions can cause access problems for users if not addressed in a timely manner; however, this is just one example of the need to find sustainable workflow options for all aspects of the program, especially as the consortium commits to continuing and expanding it. In the pilot phase, the Implementation Group was able to manage most of the work, but as the collection grows and additional DDA programs are potentially implemented, these efforts need to reside within established consortium workgroups.

\section{Conclusion}

USMAI member libraries have reported generally positive experiences with the consortium's DDA e-book pilot program, and they have expressed a desire to make it a permanent collection development activity. Ensuring that this program remains a consortial activity first requires that the DDA models remain a viable option for both libraries and publishers. Dialogue between consortia, publishers and vendors hosting content is essential; both library budgetary limitations and publisher revenue concerns must be addressed. Making data-driven decisions within the framework of the consortium's mission as well as the project's 
objectives has served USMAI well during the first two years of the pilot and must continue as the parameters of the shared e-book collection are refined. Finally, developing sustainable processing workflows will be critical in ensuring that users are able to discover all e-books available in the collection at any given time.

Honest discussion, flexibility and data sharing are necessary components in establishing and maintaining positive partnerships between and among publishers, vendors and consortial working groups, all of which contribute toward making a consortial e-book program successful. We must not lose sight of the fact that these collections exist for the benefit of our users. Keeping the conversation focused on finding workable solutions will enable all us to make informed decisions in sustaining and effectively managing consortial DDA e-book programs.

\section{References}

Bivens-Tatum, W. (2015). Creating the future of ebooks. Library Journal, 140(2), 18.

Fischer, K., Wright, M., Clatanoff, K., Barton, H., \& Shreeves, E. (2012). Give 'em what they want: A one-year study of unmediated patron-driven acquisition of e-books. College \& Research Libraries, 73(5), 469-492.

Machovec, G. (2013). Consortial ebook licensing for academic libraries. Journal Of Library Administration, 53(5/6), 390-399.

Seger, R., \& Allen, L. (2011). A publisher's perspective on PDA. Against The Grain, 23(3), 32- 
34.

Stearns, S., \& Unsworth, J. (2014, May 27). Ebook pricing hikes amount to price-gouging.

Retrieved from http://chronicle.com/blogs/letters/ebook-pricing-hikes-amount-to-pricegouging/

USMAI. (2013, December 16). About us. Retrieved from http://www.usmai.org/about-us

USMAI. (2013, December 18). Mission \& strategic plan. Retrieved from http://www.usmai.org/about-us/mission-strategic-plan

Wolfman-Arent, A. (2014, June 20). College libraries push back as publishers raise some e-book prices. Chronicle of Higher Education, 60(39), 22. 